\title{
Hematite $\left(a-\mathrm{Fe}_{2} \mathrm{O}_{3}\right)$ quantification in sedimentary magnetism: limitations of existing proxies and ways forward
}

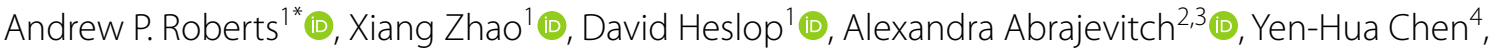 \\ Pengxiang $\mathrm{Hu}^{1} \mathbb{C}$, Zhaoxia Jiang ${ }^{5} \mathbb{0}$, Qingsong Liu ${ }^{6}$ and Brad J. Pillans ${ }^{1} \mathbb{0}$
}

\begin{abstract}
Determination of hematite contributions to sedimentary magnetizations is an important but difficult task in quantitative environmental studies. The poorly crystalline and fine-grained nature of hematite nanoparticles makes quantification of their concentrations in natural environments challenging using mineralogical and spectroscopic methods, while the weak magnetization of hematite and often significant superparamagnetic nanoparticle concentrations make quantification difficult using magnetic remanence measurements. We demonstrate here that much-used magnetic parameters, such as the S-ratio and 'hard' isothermal remanent magnetization (HIRM), tend to significantly underestimate relative and absolute hematite contents, respectively. Unmixing of isothermal remanent magnetization (IRM) acquisition curves is among the more suitable approaches for defining magnetic mineral contributions, although it has under-appreciated uncertainties that limit hematite quantification. Diffuse reflectance spectroscopy and other methods can enable relative hematite and goethite content quantification under some conditions. Combined use of magnetic, mineralogical, and spectroscopic approaches provides valuable cross-checks on estimated hematite contents; such an integrated approach is recommended here. Further work is also needed to rise to the challenge of developing improved methods for hematite quantification.
\end{abstract}

Keywords: Hematite, Magnetism, Quantification, HIRM, S-ratio, L-ratio

\section{Introduction}

Hematite is both a primary mineral and a secondary alteration product in igneous and metamorphic rocks with high oxygen fugacity (Buddington and Lindsley 1964). It tends to be more abundant in sedimentary rocks where it occurs either as detrital particles or as chemical precipitates (e.g., Cornell and Schwertmann 2003). Hematite-rich terrestrial deposits, such as sedimentary red beds, hematite-enriched soils, and lateritic weathering profiles, have become widespread on Earth's surface since $1.9 \mathrm{Ga}$ when free atmospheric oxygen became available

\footnotetext{
*Correspondence: andrew.roberts@anu.edu.au

${ }^{1}$ Research School of Earth Sciences, Australian National University,

Canberra, ACT 2601, Australia

Full list of author information is available at the end of the article
}

(Eriksson and Cheney 1992). Hematite is abundant in oxic terrestrial environments because initially formed ferric oxyhydroxides age to form hematite (Bernal et al. 1959; Berner 1969; Jiang et al. 2018). In most environments, hematite occurs alongside these initial ferric oxyhydroxides, including goethite. Hematite formation is favoured by low water contents and elevated temperatures (Berner 1969; Langmuir 1971; Maher 1986) due to dehydration of hydroxyl ions in iron oxyhydroxides, so that it becomes the environmentally important iron oxide in hot and dry environments (e.g., Larrasoaña et al. 2003).

The abundance of hematite in natural environments makes it important in sedimentary paleomagnetic and environmental magnetic studies. Iron oxides, including hematite, are also important in soil science because they are useful indicators of soil development 
(e.g., Schwertmann 1985) and contribute to soil fertility by providing a source of iron, which is an essential soil micronutrient for microbes and plant growth (e.g., Colombo et al. 2014). The need to quantify hematite contents in natural environments has led to the development of a range of magnetic, mineralogical, and spectroscopic methods for such studies. The widespread environmental occurrence of hematite as nanoparticles limits the reliability of all methods and makes hematite quantification a challenging pursuit. We here outline the main magnetic proxy parameters that are used to quantify relative, absolute, or partial sedimentary hematite contents and we evaluate their limitations and effectiveness. Our aim is to raise awareness of their limitations, to promote their constrained use alongside suitable non-magnetic methods, and to encourage development of improved methods for hematite quantification.

\section{Proxies for quantifying sedimentary hematite contents}

Iron oxides occur in trace amounts in many natural environments with concentrations below the detection limit of many bulk analytical techniques. The magnetic properties of hematite make it suitable for magnetic quantification, although its weak spontaneous magnetization at room temperature $\left(M_{\mathrm{s}}=\sim 0.4 \mathrm{Am}^{2} \mathrm{~kg}^{-1}\right)$ compared to magnetite $\left(M_{\mathrm{s}}=92 \mathrm{Am}^{2} \mathrm{~kg}^{-1}\right)$ makes this challenging. Even when small amounts of magnetite co-occur with hematite, its $\sim 230 \times$ stronger magnetization can overwhelm the magnetic contribution of hematite (e.g., Dekkers 1990; Frank and Nowaczyk 2008). Magnetic quantification of hematite, therefore, needs to meet the challenge of detecting hematite when it co-occurs with minerals like magnetite. The weak spontaneous magnetization of hematite also belies its environmental importance because its mass far exceeds that of magnetite in many natural environments. Below, we review briefly the main magnetic proxies used to estimate the relative or absolute concentration of sedimentary hematite or its coercivity variations ( $S$-ratio, 'hard' isothermal remanent magnetization (HIRM), alternating field (AF) demagnetization of an isothermal remanent magnetization (IRM) above $100 \mathrm{mT}, L$-ratio, combinations of $\mathrm{AF}$ and thermal demagnetization and low-temperature measurements, and IRM component analysis). These methods mainly exploit the coercivity of hematite. While high coercivities can be attributed to either hematite or goethite, we focus here on hematite because goethite remains unsaturated at $57 \mathrm{~T}$, with only $2-10 \%$ of such an IRM acquired below $3 \mathrm{~T}$ (Rochette et al. 2005). In contrast, hematite generally saturates magnetically near $3 \mathrm{~T}$ (Dunlop 1971; Abrajevitch et al. 2018), so it is more suitable for coercivity analysis than goethite in the fields available in most laboratories. Hematite and goethite can also be distinguished from each other using high- and low-temperature measurements (Lowrie 1990; France and Oldfield 2000; Maher et al. 2004; Lagroix and Guyodo 2017).

\section{S-ratio}

Hematite requires strong magnetic inductions up to $\sim 3 \mathrm{~T}$ to reach magnetic saturation (e.g., Dunlop 1971; Abrajevitch et al. 2018), whereas stoichiometric magnetite is saturated below $300 \mathrm{mT}$ (Fig. 1a, b). This difference is exploited to discriminate between magnetite and
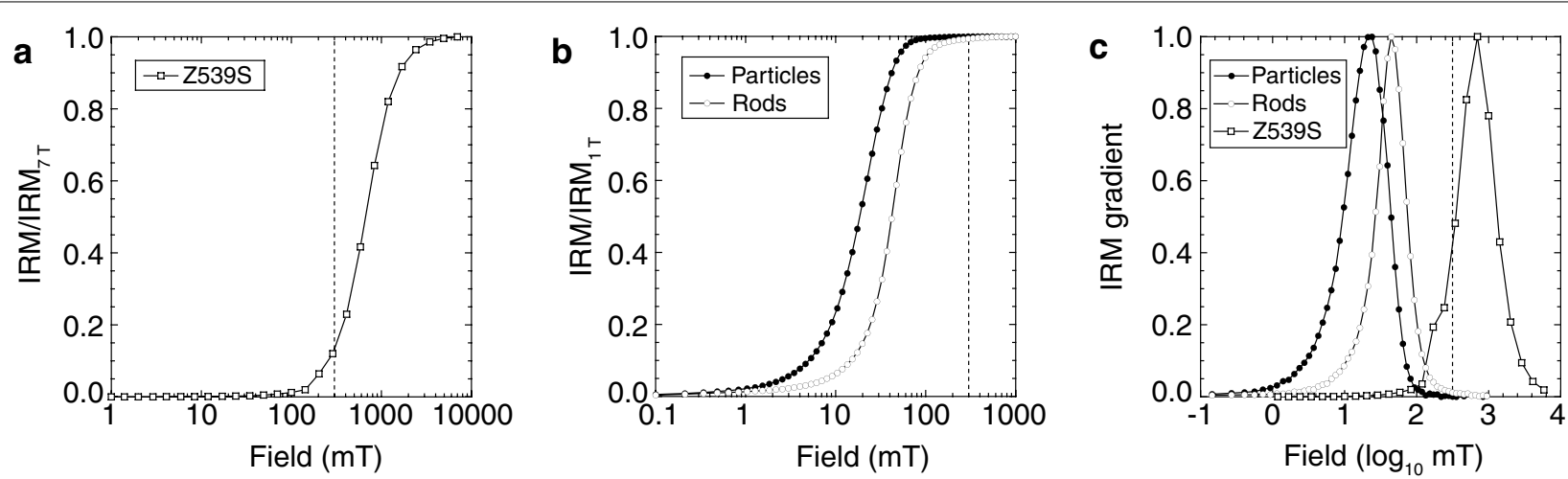

Fig. 1 Illustration of IRM acquisition in a hematite and $\mathbf{b}$ magnetite. The small IRM acquisition below $300 \mathrm{mT}$ in $\mathbf{a}$ and complete acquisition of SIRM below $300 \mathrm{mT}$ in $\mathbf{b}$ explains the basis for use of a 300-mT cut-off field to discriminate between low-coercivity magnetite and high-coercivity hematite. The sample in $\mathbf{a}$ is red pigmentary Zebra rock sample Z539S (Abrajevitch et al. 2018) and the samples in $\mathbf{b}$ are synthetic nanoparticulate magnetites ("particles" are equidimensional magnetite (40-85 nm diameter); rods are elongated with length 250-300 nm and width 60-110 nm), which were synthesized following Hu et al. (2011). c First derivative curves of the IRM (i.e., gradient) for the three samples illustrated in $\mathbf{a}$, $\mathbf{b}$, which provide a measure of the respective coercivity distributions in relation to the $300 \mathrm{mT}$ cut-off field. Dashed vertical lines represent the 300-mT cut-off field 
hematite, where any IRM acquisition above $300 \mathrm{mT}$ in natural samples is attributed to hematite or goethite in contrast to the low coercivity of (titano-)magnetite (e.g., Collinson 1968; Robinson 1986; Bloemendal et al. 1988; King and Channell 1991). Other magnetic minerals can also have coercivity above $300 \mathrm{mT}$ (e.g., surficially oxidized phases, pyrrhotite), although such high-coercivity contributions are often assumed to be only due to hematite or goethite. The contrasting magnetic saturation fields of high- and low-coercivity minerals, with minimal overlap between their coercivity distributions (Fig. 1c), provides the basis for defining the $S$-ratio, where a backfield magnetization at $300 \mathrm{mT}\left(\mathrm{IRM}_{-0.3 \mathrm{~T}}\right)$ is used as a critical cut-off field (Robinson 1986; Bloemendal et al. 1988; King and Channell 1991):

$$
S \text { - ratio }=\frac{-\mathrm{IRM}_{-0.3 \mathrm{~T}}}{\text { SIRM }} .
$$

A value of +1 is usually taken to indicate that a sample contains only a low-coercivity ferrimagnetic mineral such as magnetite, whereas values below +1 are usually taken to indicate increasing high-coercivity contributions relative to low-coercivity minerals. An alternative and popular formulation is that of Bloemendal et al. (1992):

$$
S \text { - ratio }=\frac{\left(-\frac{\mathrm{IRM}_{-0.3 \mathrm{~T}}}{\mathrm{SIRM}}\right)+1}{2} .
$$

Users must be aware of which $S$-ratio version is being used, especially when comparing data with literature values (see Fig. 2). For Eq. (1), the $S$-ratio can vary between +1 and -1 , while for Eq. (2) it can vary between +1 and 0 . The $S$-ratio provides a measure of the relative contribution of high- and low-coercivities to the SIRM (Fig. 2). Extreme minimum values are not observed for either equation even when magnetite comprises $0.05 \mathrm{wt} \%$ of the mixed sample (Fig. 2) because significant IRM acquisition also occurs below $300 \mathrm{mT}$ in hematite samples, as discussed below. Users should be aware that the $S$-ratio is highly non-linear; i.e., as the mass concentration of the high-coercivity mineral increases, the $S$-ratio does not decrease linearly (Fig. 2) (Frank and Nowaczyk 2008).

\section{'Hard' IRM (HIRM)}

HIRM is also defined using a 300-mT cut-off field (Robinson 1986; Bloemendal et al. 1988; King and Channell 1991):

$$
\mathrm{HIRM}=\frac{\left(\mathrm{SIRM}+\mathrm{IRM}_{-0.3 \mathrm{~T}}\right)}{2} .
$$

HIRM provides a measure of the absolute contribution of high-coercivity minerals to magnetic remanence and has been used extensively in quantitative environmental

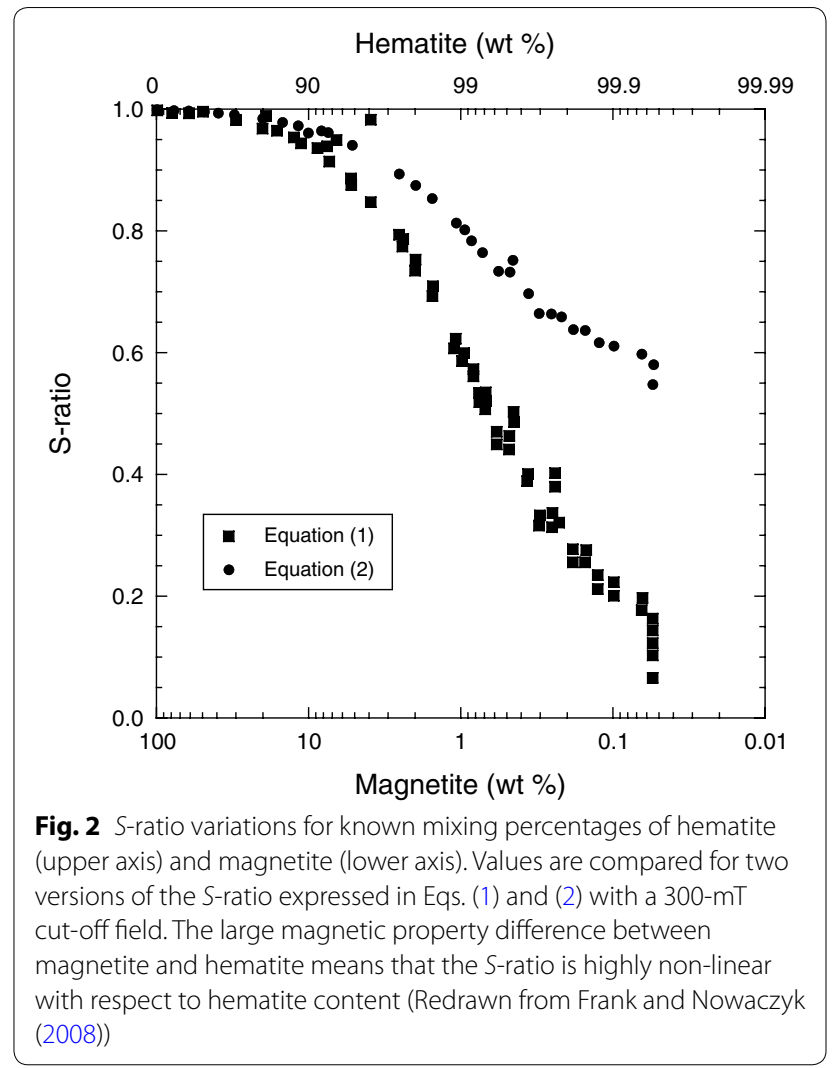

magnetic studies (e.g., Robinson 1986; Bloemendal et al. 1988; Rosenbaum et al. 1996; Yamazaki and Ioka 1997; Hounslow and Maher 1999; Larrasoaña et al. 2003; Quinton et al. 2011; Reynolds et al. 2014), although difficulties associated with its applicability have also been pointed out (e.g., Liu et al. 2007; Hao et al. 2009). It treats any acquisition of IRM above $300 \mathrm{mT}$ as representing the 'hematite' signal, which is reasonable by comparison to Fig. 1a if hematite is the only high-coercivity mineral present in a sample. Hu et al. (2016) defined a more general version that makes use of different cut-off fields $(x$ $\mathrm{mT}$, where $x$ is variable and negative) that can be used to quantify hematite with variable coercivity ranges:

$$
\mathrm{HIRM}_{x \mathrm{mT}}=\frac{\left(\mathrm{SIRM}+\mathrm{IRM}_{x \mathrm{mT}}\right)}{2} .
$$

\section{IRM after AF demagnetization at $>100 \mathrm{mT}$}

Various alternatives to HIRM have been proposed as measures of the absolute abundance of the high-coercivity hematite fraction in natural samples. For example, Liu et al. (2002) showed that HIRM determination can be problematic when the IRM carried by hematite or goethite is masked by a coexisting strongly magnetic mineral, such as magnetite, because HIRM can have a similar magnitude as measurement errors. Liu et al. 
(2002) proposed a cyclic direct current (DC) demagnetization of SIRM to obtain a residual remanence that does not amplify errors due to addition of the equivalent positive forward-field SIRM and negative backfield magnetization in Eq. (3). Alternative approaches for estimating high-coercivity hematite contents have been proposed for U-channel measurements. Strong-field IRM measurements can be difficult to measure because the magnetization can exceed the dynamic range of U-channel magnetometers. Larrasoaña et al. (2003) imparted an IRM in a $0.9 \mathrm{~T}$ field to U-channel samples followed by AF demagnetization at $120 \mathrm{mT}$ to compensate for the fact that the SIRM may not be measurable in such systems. This approach should remove the total contribution due to magnetite and leave only the IRM due to the highest coercivity component. The weak remaining magnetization can then be measured readily within the dynamic range of the magnetometer. Maher et al. (2004) proposed an alternative approach for characterizing IRM acquisition in high-coercivity minerals by subjecting samples to AF demagnetization at $100 \mathrm{mT}$ to remove magnetite contributions after each IRM acquisition step. Used in tandem with low-temperature magnetic measurements, this approach has value in identifying and separating magnetic contributions due to hematite and goethite.

\section{L-ratio}

Liu et al. (2007) pointed out that hematite and goethite can have highly variable coercivity (Fig. 3a, b), which can complicate $S$-ratio and HIRM interpretations. Such coercivity variations can mean that the $S$-ratio and HIRM are not necessarily straightforward proxies of the relative and absolute concentrations, respectively, of high-coercivity minerals. To enable detection of such issues, Liu et al. (2007) proposed the $L$-ratio (Fig. 3c), which is the ratio of two remanences after AF demagnetization (using cyclic DC demagnetization) at $100 \mathrm{mT}$ and $300 \mathrm{mT}$ of an IRM that was imparted in a 1-T field:

$$
L-\text { ratio }=\frac{I_{\mathrm{IRM}} \mathrm{AF} 300 \mathrm{mT}}{\mathrm{IRM}_{\mathrm{AF} @ 100 \mathrm{mT}}} .
$$

Equivalently, the $L$-ratio can be defined using Eq. (4) as (Liu et al. 2007):

$$
L-\text { ratio }=\frac{\mathrm{HIRM}_{300 \mathrm{mT}}}{\mathrm{HIRM}_{100 \mathrm{mT}}} .
$$

Based on the variable coercivity of hematite and goethite, Liu et al. (2007) envisaged that other peak AF values instead of those specified in Eq. (5) might be preferable in some situations. Assessment of appropriate alternative values would require measurement of a complete coercivity spectrum rather than only at these simple cut-off fields. Original and modified versions of the $L$-ratio have proven to be valuable in varied environmental applications (e.g., Hao et al. 2009; Lyons et al. 2010; Oldfield et al. 2014; Shi et al. 2014).

\section{Combined AF and thermal demagnetization and low-temperature approaches}

Combining AF and thermal demagnetization provides a further means of isolating contributions due to hematite. For example, Kodama and Dekkers (2004) applied a $13 \mathrm{~T}$ field to samples, which was followed by AF demagnetization at $200-280 \mathrm{mT}$ to remove contributions due to magnetite, and then by thermal demagnetization at
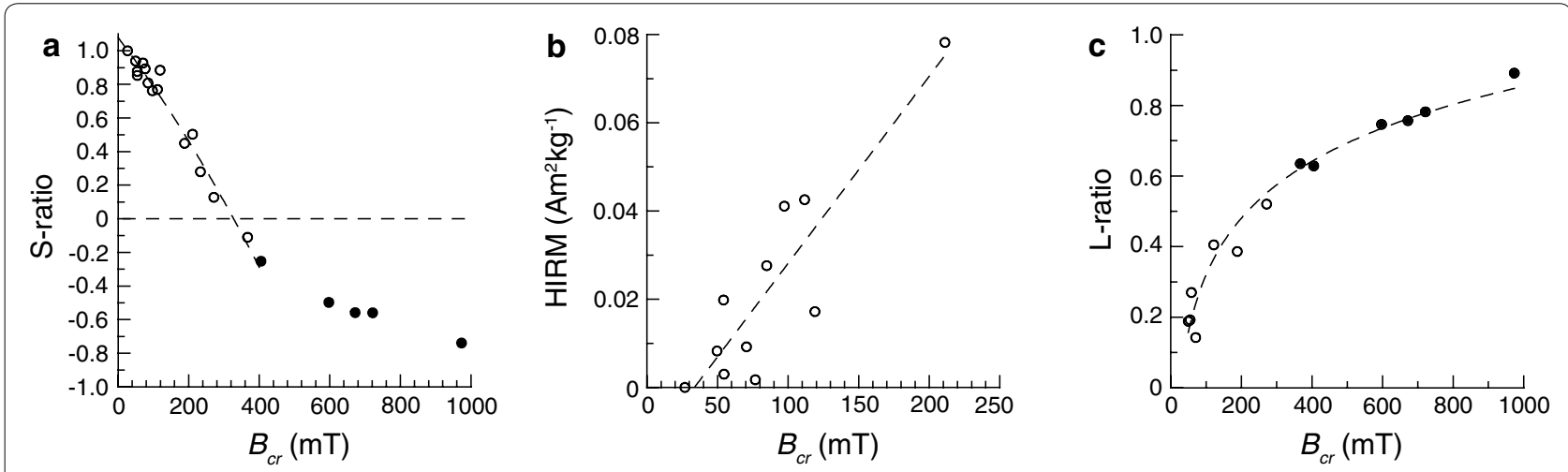

Fig. 3 Coercivity variations and their influence on S-ratio and HIRM. a S-ratio (Eq. 1) and $\mathbf{b}$ HIRM versus coercivity of remanence $\left(B_{\mathrm{cr}}\right)$, where the $S$-ratio decreases with increasing coercivity and HIRM increases with increasing coercivity because more IRM is acquired above $300 \mathrm{mT}$ as coercivity hardens. Such coercivity changes represent compositional differences in the analysed high-coercivity minerals, which can be assessed with $\mathbf{c}$ the $L$-ratio. Constant $L$-ratio values indicate consistent magnetic properties of the high-coercivity component, and changing values represent variable coercivity. Open circles represent synthetic Al-substituted hematites and solid circles represent Al-substituted goethites (Redrawn, including relationships for curve fits, from Liu et al. (2007)) 
$120{ }^{\circ} \mathrm{C}$ to remove goethite contributions. The remaining IRM was then interpreted to represent the hematite contribution. As is the case for all magnetic remanencebased estimations of hematite contents discussed here, such approaches do not include contributions due to the hyperfine superparamagnetic (SP) fraction. Lowtemperature magnetic measurements add value when such nanoparticles are abundant because their contributions can be quantified by lowering the measurement temperature to below the blocking temperature of these particles. IRM acquisition experiments at low temperatures can provide improved diagnosis of such contributions (e.g., Bógalo et al. 2001). Guyodo et al. (2006) and Lagroix and Guyodo (2017) developed a further experimental protocol that takes advantage of these field and temperature dependencies of the magnetic properties of important magnetic minerals to separate magnetic contributions due to hematite, magnetite, maghemite, and goethite. The equipment required for such measurements is not widely available and the measurement sequence is time-consuming, but it is an effective method for semi-quantitative estimation of the contributions of these magnetic minerals (Lagroix and Guyodo 2017).

\section{IRM component analysis}

Taking the first derivative of IRM acquisition/backfield demagnetization curves and fitting constituent components mathematically enables quantification of magnetic components in a sample (e.g., Robertson and France 1994; Kruiver et al. 2001; Heslop et al. 2002; Egli 2004). Magnetic components have continuous coercivity distributions and such fitting avoids a sharp cut-off at $300 \mathrm{mT}$ to enable direct identification of the full low- or highcoercivity component, which will inevitably overlap to some extent. Hematite components will be evident in representations of the gradient of IRM acquisition curves (Fig. 1c), especially if measurements are made in saturating fields. IRM components measured to $7 \mathrm{~T}$ are illustrated in Fig. 4 in which the entire hematite component is captured (Abrajevitch et al. 2014, 2015). For samples containing only pigmentary hematite, the peak coercivity is higher for a non-uniformly distributed (Fig. 4a) than for a uniformly distributed pigment (Fig. 4b), although

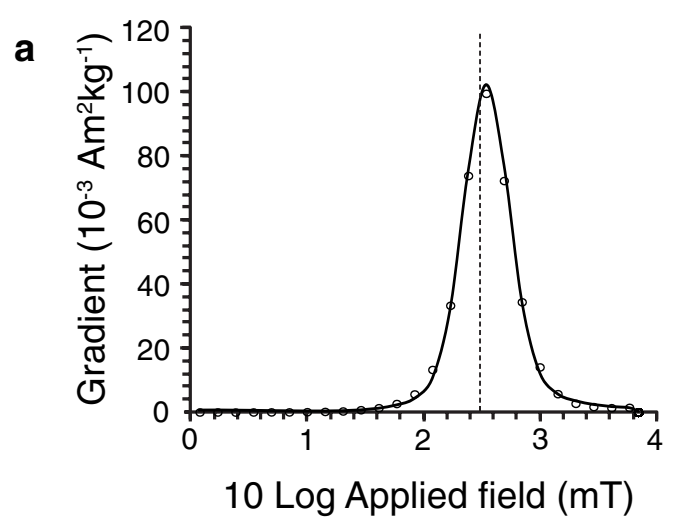

C

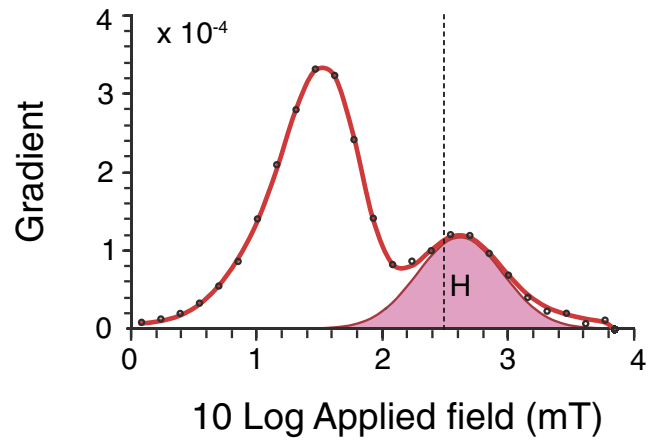

b
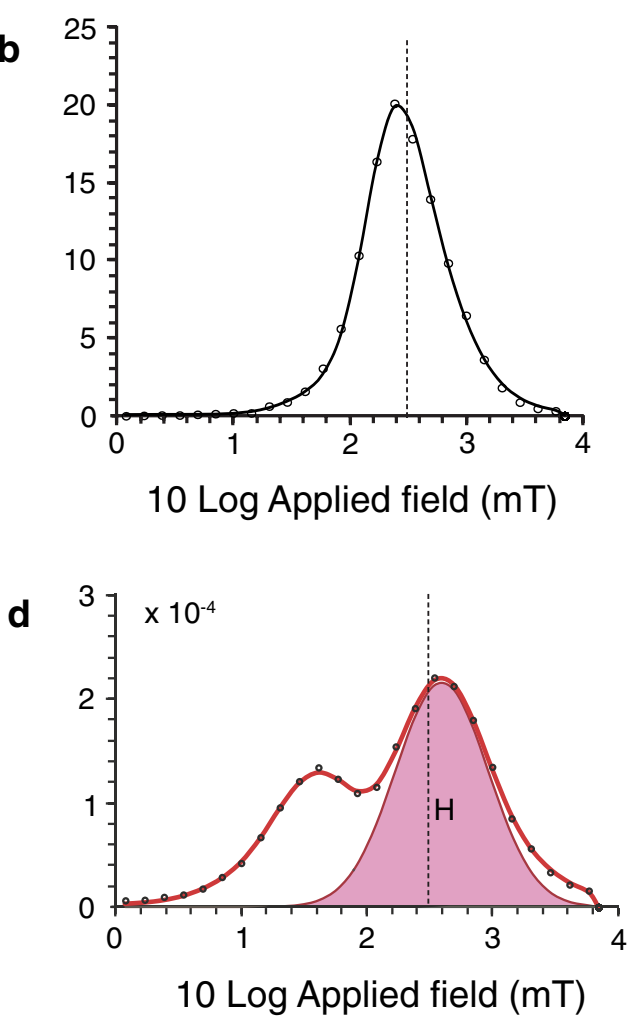

Fig. 4 First derivative of IRM acquisition (gradient) curves and hematite components for 7-T maximum applied fields. Results for hematite pigments in a decorative 'print stone' from the Mount McRae Shale Formation, Western Australia (Abrajevitch et al. 2014): a hematite print stone pigment (sample pps11) and $\mathbf{b}$ uniform pigment (sample TOM07). Results from Abrajevitch et al. (2015) for: c Paleogene limestone $21 \mathrm{~cm}$ above the K-Pg boundary at Bottaccione Gorge, Italy, and $\mathbf{d}$ limestone $46.5 \mathrm{~cm}$ below the boundary. Abrajevitch et al. (2015) identified five components; for clarity, only the hematite (labelled H) component of interest here is shown. Dashed vertical lines represent the 300-mT cut-off field 
the latter has a higher coercivity tail that requires high applied fields to achieve saturation (Abrajevitch et al. 2014). Notably, these samples have significant coercivity distributions $<300 \mathrm{mT}$ (Fig. 4a, b). Most natural samples contain multiple magnetic minerals, as illustrated in the bimodal coercivity distributions in Fig. 4c, d for limestone/shale interbeds across the Cretaceous-Paleogene (K-Pg) boundary at Bottaccione Gorge, Italy (Abrajevitch et al. 2015). A limestone from $21 \mathrm{~cm}$ above the $\mathrm{K}-$ Pg boundary was interpreted by Abrajevitch et al. (2015) to contain five magnetic components, which are typical of pelagic limestones (e.g., Roberts et al. 2013), and include detrital magnetite, the biogenic soft and biogenic hard magnetite components of Egli (2004), hematite, and goethite. We focus here on the nature of the hematite component and do not show these other components in Fig. 4c, d. A sample from below the K-Pg boundary is also interpreted to contain the same components, with a larger hematite component (Fig. 4d). Like the pigmentary hematite illustrated in Fig. 4c, d, a significant fraction of the fitted hematite coercivity distribution extends below $300 \mathrm{mT}$. These examples demonstrate that IRM component analysis is suitable for characterizing hematite components, particularly when large inducing fields are used. At typical maximum applied fields of $1 \mathrm{~T}$, hematite components will still be well defined, although they are truncated (Fig. 4). Routine application of fields of the order of several Tesla is preferable for defining hematite components.

\section{What are the limitations of magnetic proxies for hematite content?}

Use of 300-mT cut-off fields in the S-ratio, HIRM, and other parameters in rock magnetism are convenient, but this considers only part of the coercivity distribution for hematite. This assumption would be reasonable if all samples behave like those illustrated in Fig. 1a. While much of the remanence of the sample illustrated in Fig. 1a is acquired above $300 \mathrm{mT}$, a considerable IRM is carried by hematite particles with coercivity below $300 \mathrm{mT}$ for many natural mixed and pure hematite samples (Figs. 4 and 5). The dominance of IRM acquisition at applied fields $>300 \mathrm{mT}$ illustrated in Fig. 1a is due to the presence of magnetically hard stable SD hematite in sample Z539S. In contrast, many natural hematite samples have abundant hyperfine SP nanoparticle concentrations (e.g., Creer 1961; Collinson 1969). Hematite particle size distributions in such samples will likely span the magnetically unstable SP to stable SD size range, which will give rise to a substantial low-coercivity distribution. In addition, isomorphous cation substitution (e.g., $\mathrm{Al}^{3+}$ for $\mathrm{Fe}^{3+}$ ) into the hematite lattice tends to reduce the particle size,
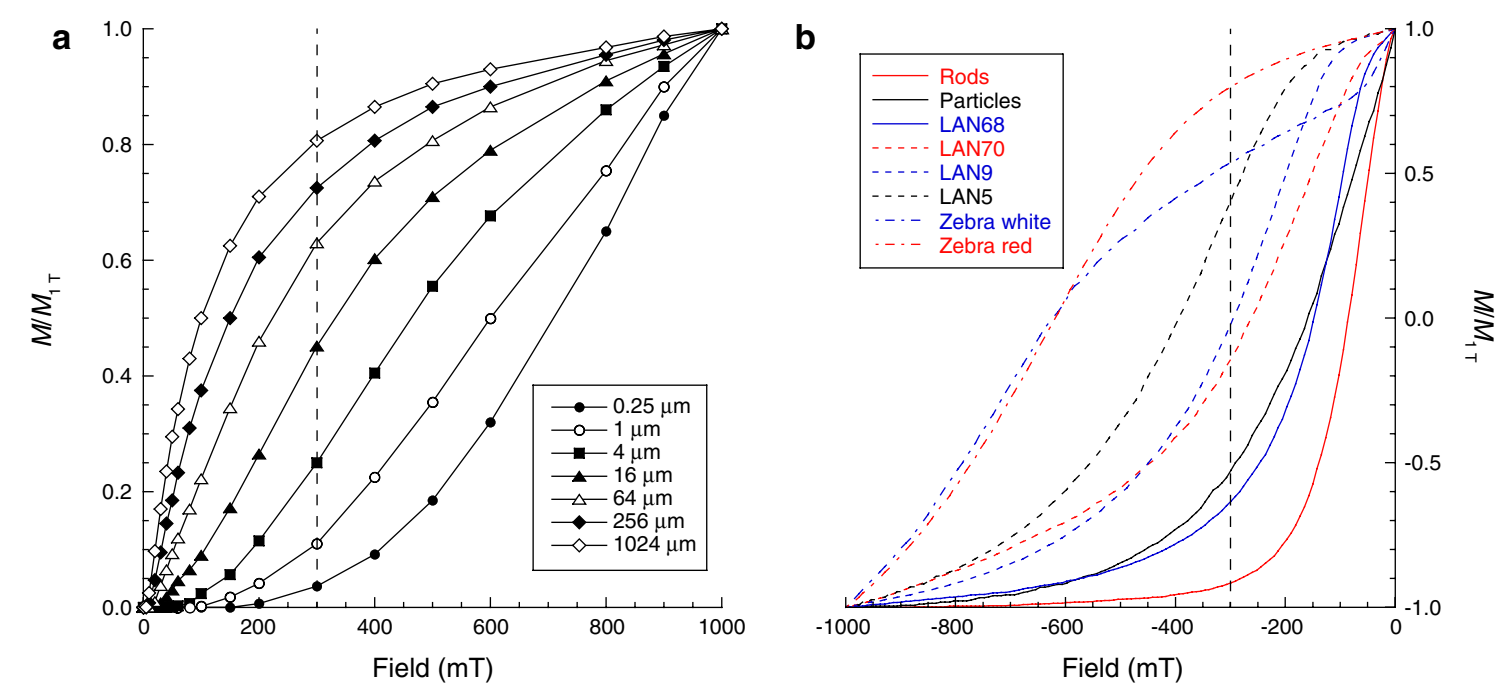

Fig. 5 IRM acquisition and backfield demagnetization curves for hematite samples. a IRM acquisition curves for known hematite size fractions, where finer sizes are more resistant to acquisition (and vice versa). Redrawn from Thompson (1986). b Backfield demagnetization curves for SD hematite samples measured at the Australian National University (where DC demagnetization curves are equivalent to IRM acquisition curves with twice the amplitude and opposite slope for non-interacting SD particles). Two samples (particles, zebra white) have steep initial slopes due to magnetically soft hematite near the superparamagnetic/SD threshold size and are then dominated by higher coercivities. Zebra samples are pigmentary hematite from Abrajevitch et al. (2018). LAN samples are natural nanocrystalline hematite samples from deeply weathered regolith from Lancefield South gold mine, Western Australia.'Particles' are equidimensional hematite nanoparticles (45-85 nm particle sizes) and 'rods' are nanorods (250-350 nm (length) × 50-100 nm (width)) that were synthesized hydrothermally (Islam et al. 2012). Dashed vertical lines represent the 300-mT cut-off field 
which can lower the coercivity in many samples (Jiang et al. 2012). Thus, cation substitution can also contribute to significant coercivity distributions $<300 \mathrm{mT}$. The SP/ SD threshold size is estimated to be $25-20 \mathrm{~nm}$ for stoichiometric hematite (Banerjee 1971; Özdemir and Dunlop 2014) and $17 \mathrm{~nm}$ for Al-substituted hematite (Jiang et al. 2014). Hematite particles below these threshold sizes are abundant in natural environments (e.g., Mehra and Jackson 1960; Schwertmann 1991), which is consistent with commonly observed magnetic viscosity in hematite (e.g., Creer 1961; Collinson 1969).

For hematite samples with known particle size (Fig. 5a), coarser particles $(\sim 1 \mathrm{~mm})$ have low coercivities and finer particles $(250 \mathrm{~nm})$ have higher coercivities (Thompson 1986). Finer hematite nanoparticles than those illustrated in Fig. 5a tend to be of greatest environmental and paleomagnetic importance. The significant IRM acquisition below $300 \mathrm{mT}$ in Figs. 4 and 5 is ignored when using a 300 -mT cut-off field to calculate the $S$-ratio, HIRM, and other parameters. These parameters, therefore, only provide measures of the highest coercivity hematite fraction rather than of the entire hematite component. All remanence acquisition above $300 \mathrm{mT}$ is attributed correctly to hematite, but the significant remanence acquisition from 0 to $300 \mathrm{mT}$ (e.g., Figs. 4 and 5) will be attributed to other low-coercivity minerals. The $S$-ratio will, therefore, almost always provide an under-estimate of the relative hematite fraction, and HIRM will almost always provide an under-estimate of the absolute hematite concentration. These parameters are interpreted commonly in terms of magnetite versus hematite for the $S$-ratio and in terms of the absolute hematite content for HIRM, without recognition that they underestimate the hematite content. For example, for the 1-T maximum applied field used in Fig. 5a, $S$-ratio values vary up to 0.8 despite the fact that the samples contain no magnetite. $S$-ratios up to +1 are illustrated in Fig. 3a for synthetic samples that contain only nanophase hematite or goethite (Liu et al. 2007). Also, owing to instrumental limitations, IRM acquisition experiments often involve measurement of hematite-bearing samples to maximum applied fields of $1 \mathrm{~T}$. This will cause further underestimation of hematite contents when using the $S$-ratio and HIRM if a highercoercivity hematite component continues to acquire an IRM above $1 \mathrm{~T}$, as in Figs. 4 and 5. Routine underestimation of hematite contents with these magnetic methods deserves to be understood more widely. Use of such parameters could lead to significant misinterpretations, especially in quantitative environmental magnetic studies. To minimize such issues, we recommend combined use of magnetic and non-magnetic quantification methods as outlined below.
Three other issues related to the $S$-ratio also deserve consideration. First, alternative formulations of the $S$-ratio with lower cut-off backfield values (e.g., $100 \mathrm{mT}$ ) in the numerator of Eqs. (1) or (2) are often used to assess magnetically soft components (e.g., Stober and Thompson 1979; Thompson and Oldfield 1986; Stoner et al. 1996; Frank and Nowaczyk 2008). Users should be aware of the ambiguities inherent to such low-coercivity ranges, which are best used when magnetic assemblages are well constrained by other analyses. When the magnetic mineral assemblage under investigation is well understood, use of variable cut-off fields can be valuable. Second, Kruiver and Passier (2001) demonstrated that $S$-ratio values several percent below +1 can occur without addition of a high-coercivity mineral like hematite. $S$-ratio values $<1$ can be due to coercivity hardening by surface oxidation of magnetite (e.g., Cui et al. 1994; van Velzen and Zijderveld 1995). Third, when using the $S$-ratio, it should be noted that standard statistics, such as arithmetic means and standard deviations, do not apply. This is because the $S$-ratio provides relative rather than absolute information and is a bivariate measure represented by the low- and high-coercivity contributions that both lie in the range 0 to +1 and that sum to one (Heslop 2009). The low- and high-coercivity components are fundamentally interdependent, so descriptive statistics for the $S$-ratio can be obtained by considering the ratio of the low- and high-coercivity components together with an additivelog-ratio transform that preserves the relative nature of the data (Heslop 2009). $S$-ratio users are directed to Heslop (2009) for details of appropriate statistics to use when reporting $S$-ratio values.

The highly variable coercivity of hematite (Figs. 4 and 5) means that the usefulness of simple parameters such as the $S$-ratio and HIRM will depend on the properties of hematite in a sample. Hao et al. (2009) demonstrated the difficulty in quantifying hematite contents from such simple parameters in environments with changing sediment source, cation substitution, particle size distribution, and varying hematite/goethite contents. These variations contribute to continuous $L$-ratio variations throughout a 22-Myr eolian sedimentary sequence and demonstrate the usefulness of the $L$-ratio in detecting situations where interpretation of the $S$-ratio and HIRM become complicated by variable coercivity distributions in hematite/goethite-bearing samples.

\section{Are there better options for hematite quantification?}

IRM component analysis appears to be the most suitable of the methods discussed because it enables estimation of continuous, non-truncated coercivity distributions. If a hematite component is well defined, 
its magnitude can be calculated as a proportion of the total magnetization to allow hematite quantification even if magnetic saturation is not achieved. The 7-T maximum fields used in Fig. 4 capture the full hematite component. Most studies use lower maximum applied fields, which need to be large enough to define the hematite component. However, IRM curve analysis still has limitations for hematite quantification. Most environmental magnetic studies provide evidence to identify whether a magnetic component is present or absent, which provides semi-supervised IRM unmixing that helps to reduce the non-uniqueness that is inherent to unmixing (Heslop 2015). Nevertheless, the precise coercivity distribution of a magnetic component will remain unknown, as will its magnitude. This means that determining unique component fits to IRM acquisition curves remains a challenge, and uncertainties associated with non-uniqueness of hematite component fits could exceed those for the $S$-ratio and HIRM. We conclude, therefore, that there are substantial limitations for all existing magnetic proxies for hematite content. Additionally, room temperature remanencebased methods will not quantify ultrafine SP contents, which can be significant in hematite (e.g., Creer 1961; Collinson 1969).

Although we lack simple ways to reliably quantify hematite contents in natural samples, the ambiguities that are inherent to hematite quantification can be reduced if proxies are used critically and in combination. For example, IRM component analysis can be used to check the coercivity range of hematite and the $L$-ratio can be used to check for variations in these ranges. If the $L$-ratio is variable, conventional use of the $S$-ratio and HIRM is unreasonable (Liu et al. 2007). Other methods can also be used to quantify hematite components. For example, diffuse reflectance spectroscopy (DRS) is used widely in soil science to estimate hematite and goethite concentrations. Hematite and goethite have distinct characteristic DRS bands, so the goethite/hematite ratio and abundance can be determined sensitively $(<0.5 \mathrm{wt} \%)$ from DRS measurements when these minerals are the dominant iron oxides in a soil (e.g., Deaton and Balsam 1991; Scheinost et al. 1998; Torrent and Barrón 2002; Torrent et al. 2007). Most sedimentary environments contain iron oxide mixtures, which add ambiguity to interpretation of DRS results (e.g., Scheinost et al. 1998; Torrent and Barrón 2002). Further ambiguities are caused by variable cation substitution, grain size, and crystallinity, which alter the positions and intensity of characteristic DRS bands. Al-substitution also has a major impact on the coercivity distribution of hematite (e.g., Liu et al. 2007). $\mathrm{Hu}$ et al. (2016) integrated DRS and magnetic results to identify ambiguities produced by $\mathrm{Al}$-substitution. They demonstrated that combining DRS and magnetic analyses can be valuable for hematite quantification when $\mathrm{Al}$ contents are $<\sim 8 \%$.

Quantification of the abundance of ultrafine hematite and goethite nanoparticles, including as grain coatings, which fall in the magnetic SP size range that does not contribute to the remanence-based magnetic measurements discussed here is a challenge for most magnetic (including Mössbauer spectroscopy) and other methods. Soil scientists have developed partial dissolution techniques that exploit the solubility of such fine particles (e.g., Mehra and Jackson 1960; Schwertmann 1991), where the fraction of dissolved minerals is quantified using analytical chemistry. Such stepwise dissolution techniques have been incorporated in environmental magnetic studies mainly in relation to understanding signals due to the strongly magnetic minerals magnetite and maghemite (e.g., Verosub et al. 1993; Hunt et al. 1995; van Oorschot and Dekkers 1999). While stepwise dissolution methods are time-consuming, they can provide valuable insights into iron oxide abundances along with magnetic and DRS results. For example, Hu et al. (2013) combined these methods to quantify detrital and pedogenic magnetite, maghemite, hematite, and goethite contributions in a Chinese loess-paleosol sequence. It should be noted, however, that such methods tend to be calibrated with well-crystallized standards that may not be representative of poorly crystalline natural iron oxide nanoparticles.

Other methods that are used to quantify iron oxides in natural environments include voltammetry, Mössbauer spectroscopy, and X-ray diffraction (XRD). Voltammetry exploits the electroactivity of compounds, which can be dissolved reductively at potentials that are specific to their mineralogy and reactivity. By scanning over a range of potentials and monitoring the potential at which a reaction occurs, it is possible to specify the type of iron (oxy-) (hydr-) oxides present. Voltammetry has proven to be a useful technique for quantifying low concentrations of poorly crystalline iron oxides, including hematite (e.g., Memon et al. 2009), and has been used alongside magnetic methods (e.g., van Oorschot et al. 2001; Grygar et al. 2003). Mössbauer spectroscopy is a powerful technique that enables direct identification and quantification of iron (oxy-) (hydr-) oxides in soils and sediments, even for mixtures of iron-bearing minerals. Hematite has a large hyperfine field that assists its identification and discrimination from other iron (oxy-) (hydr-) oxides (Vandenberghe et al. 2000). Mössbauer spectroscopy has not been used particularly widely in environmental magnetic studies despite its usefulness for identifying magnetic minerals, including estimating hematite contents (e.g., Maher et al. 2003). Like other methods, variable stoichiometry, Al-substitution, crystallinity, particle size, and 
surface effects in nanoparticles can limit the diagnostic value of results and need to be constrained independently (Vandenberghe et al. 2000). XRD analysis is among the most diagnostic methods for identifying crystalline materials, although the relatively low concentration of iron (oxy-) (hydr-) oxides in sediments and soils usually requires some form of magnetic mineral concentration to provide meaningful results. Hematite has been identified widely in such analyses (Torrent et al. 1980; Yamazaki and Ioka 1997; Deng et al. 2000; Maher et al. 2003). The usually unknown effectiveness of mineral separation and concentration methods means that XRD analysis tends to be used for mineral identification rather than for quantifying mineral contents and poorly crystalline nanoparticles are invisible to XRD analysis. XRD analysis can also be used along with selective dissolution techniques, where comparison of XRD spectra before and after dissolution treatment (referred to as differential XRD) enables determination (by subtraction) of the XRD pattern for the dissolved iron oxide fraction (Schulze 1981).

Even from such a brief overview, it is evident that quantifying ultrafine particle concentrations is a challenge for all methods. We conclude that combined use of magnetic and other mineralogical and spectroscopic methods provides the best prospect for obtaining reasonable quantitative estimates of sedimentary hematite contents.

\section{Conclusions}

The $S$-ratio and HIRM are much-used magnetic parameters that underestimate relative and absolute concentrations, respectively, of hematite. Use of fixed cut-off fields to define these parameters ignores the often-significant contribution of low-coercivity hematite and attributes it to another low-coercivity phase. Many environmental interpretations depend on magnetic mineral content estimation, so reliable quantification approaches are needed. IRM component unmixing involves identification of continuous coercivity distributions so it does not suffer from the truncation produced by use of fixed cut-off fields, but its non-uniqueness and associated uncertainties are not as well appreciated as they should be and uncertainties are likely to be as large as for the $S$-ratio and HIRM. Diffuse reflectance spectroscopy is used widely to assess and validate magnetic hematite quantification. It has its own ambiguities, particularly in environments that contain mixed iron oxides with variable cation substitution, grain size, and crystallinity, although it provides a valuable independent test of magnetic methods. Other methods such as selective dissolution of iron oxides, voltammetry, Mössbauer spectroscopy, and XRD analysis can be used to provide further valuable constraints on hematite quantification. We point to the limitations of magnetic parameters used for hematite quantification to encourage their informed use along with other methods to cross-check results. Such cross-checking enables assessment of the possibility that different parts of the hematite assemblage have been detected with different methods. We also encourage development of methods for more reliable hematite quantification. Despite their limitations, integrated use of existing hematite proxies enables proxy cross-comparison and validation, and their use has proven value in paleoenvironmental and paleoclimatic studies.

\section{Supplementary information}

Supplementary information accompanies this paper at https://doi. org/10.1186/s40562-020-00157-5.

Additional file 1. Data presented in Figures 1, 4 and 5.

\section{Acknowledgements}

We thank the Editors Andrew Tien-Shun Lin and Kenji Satake for their assistance, reviewers Mark Dekkers and Toshi Yamazaki for constructive comments that improved the paper, and several colleagues for encouraging publication of this paper based on an oral presentation at the 2019 AGU Fall Meeting.

\section{Authors' contributions}

APR conceived the paper in discussion with DH and XZ. All co-authors contributed samples and/or data and participated in manuscript refinement. All authors read and approved the final manuscript.

\section{Funding}

This work was supported financially by the Australian Research Council (ARC) through Grant DP200100765. The ARC had no role in the study design or in the collection, analysis, or interpretation of data, or in writing the manuscript.

\section{Availability of data}

Most of the data presented here have been published before. Data presented in Figs. 1, 4, and 5 are included in an Additional file 1.

\section{Competing interests}

The authors declare no competing interests.

\section{Author details}

${ }^{1}$ Research School of Earth Sciences, Australian National University, Canberra, ACT 2601, Australia. ${ }^{2}$ Department of Earth Sciences, Ehime University, Matsuyama, Japan. ${ }^{3}$ Institute of Tectonics and Geophysics, Russian Academy of Sciences, Khabarovsk, Russia. ${ }^{4}$ Department of Earth Sciences, National Cheng Kung University, Tainan 70101, Taiwan. ${ }^{5}$ Key Laboratory of Submarine Geosciences and Prospecting Techniques, Ministry of Education, and College of Marine Geosciences, Ocean University of China, Qingdao 266100, People's Republic of China. ${ }^{6}$ Centre for Marine Magnetism, Department of Ocean Science and Engineering, Southern University of Science and Technology, Shenzhen 518055, People's Republic of China.

Received: 12 March 2020 Accepted: 6 June 2020

Published online: 15 June 2020

\section{References \\ Abrajevitch A, Pillans BJ, Roberts AP (2014) Haematite pigmentation events and palaeomagnetic recording: implications from the Pilbara Print Stone, Western Australia. Geophys J Int 199:658-672 \\ Abrajevitch A, Font E, Florindo F, Roberts AP (2015) Asteroid impact vs. Deccan eruptions: the origin of low magnetic susceptibility beds below the Cre- taceous-Paleogene boundary revisited. Earth Planet Sci Lett 430:209-223}


Abrajevitch A, Pillans BJ, Roberts AP, Kodama K (2018) Magnetic properties and paleomagnetism of Zebra Rock, Western Australia: chemical remanence acquisition in hematite pigment and Ediacaran geomagnetic field behavior. Geochem Geophys Geosyst 19:732-748

Banerjee SK (1971) New grain size limits for palaeomagnetic stability in haematite. Nat Phys Sci 232:15-16

Bernal JD, Dasqupta DR, Mackay AL (1959) The oxides and hydroxides of iron and their structural inter-relationships. Clay Miner Bull 4:15-30

Berner RA (1969) Goethite stability and the origin of red beds. Geochim Cosmochim Acta 33:267-273

Bloemendal J, Lamb B, King JW (1988) Paleoenvironmental implications of rock-magnetic properties of late Quaternary sediment cores from the eastern Equatorial Atlantic. Paleoceanography 3:61-87

Bloemendal J, King JW, Hall FR, Doh S-J (1992) Rock magnetism of late Neogene and Pleistocene deep-sea sediments: relationship to sediment source, diagenetic processes, and sediment lithology. J Geophys Res 97:4361-4375

Bógalo MF, Heller F, Osete ML (2001) Isothermal remanence experiments at room and at liquid nitrogen temperature: application to soil studies. Geophys Res Lett 28:419-422

Buddington AF, Lindsley DH (1964) Iron-titanium oxide minerals and synthetic equivalents. J Petrol 5:310-357

Collinson DW (1968) An estimate of the haematite content of sediments by magnetic analysis. Earth Planet Sci Lett 4:417-421

Collinson DW (1969) Investigations into the stable remanent magnetization of sediments. Geophys J R Astron Soc 18:211-222

Colombo C, Palumbo G, He JZ, Pinton R, Cesco S (2014) Review on iron availability in soil: interaction of Fe minerals, plants, and microbes. I Soil Sediment 14:538-548

Cornell RM, Schwertmann U (2003) The iron oxides: structure, properties, reactions, occurrences and uses. Wiley, Weinheim, p 664

Creer KM (1961) Superparamagnetism in red sediments. Geophys J R Astron Soc 5:16-28

Cui YL, Verosub KL, Roberts AP (1994) The effect of maghemitization on large multi-domain magnetite. Geophys Res Lett 21:757-760

Deaton BC, Balsam WL (1991) Visible spectroscopy: a rapid method for determining hematite and goethite concentration in geological materials. J Sediment Res 61:628-632

Dekkers MJ (1990) Magnetic properties of natural goethite-III. Magnetic behaviour and properties of minerals originating from goethite dehydration during thermal demagnetization. Geophys J Int 103:233-250

Deng CL, Zhu RX, Verosub KL, Singer MJ, Yuan BY (2000) Paleoclimatic significance of the temperature-dependent susceptibility of Holocene loess along a NW-SE transect in the Chinese loess plateau. Geophys Res Lett 27:3715-3718

Dunlop DJ (1971) Magnetic properties of fine-particle hematite. Ann Géophys 27:269-293

Egli R (2004) Characterization of individual rock magnetic components by analysis of remanence curves, 1. Unmixing natural sediments. Stud Geophys Geod 48:391-446

Eriksson PG, Cheney ES (1992) Evidence for the transition to an oxygen-rich atmosphere during the evolution of red beds in the Lower Proterozoic sequences of southern Africa. Precambrian Res 54:257-269

France DE, Oldfield F (2000) Identifying goethite and hematite from rock magnetic measurements of soils and sediments. J Geophys Res 105:2781-2795

Frank U, Nowaczyk NR (2008) Mineral magnetic properties of artificial samples systematically mixed from haematite and magnetite. Geophys J Int 175:449-461

Grygar T, Dedecek J, Kruiver PP, Dekkers MJ, Bezdicka P, Schneeweiss O (2003) Iron oxide mineralogy in late Miocene red beds from La Gloria, Spain: rock-magnetic, voltammetric and vis spectroscopy analyses. Catena 53:115-132

Guyodo Y, LaPara TM, Anschutz AJ, Penn RL, Banerjee SK, Geiss CE, Zanner W (2006) Rock magnetic, chemical and bacterial community analysis of a modern soil from Nebraska. Earth Planet Sci Lett 251:168-178

Hao QZ, Oldfield F, Bloemendal J, Torrent J, Guo ZT (2009) The record of changing hematite and goethite accumulation over the past $22 \mathrm{Myr}$ on the Chinese Loess Plateau from magnetic measurements and diffuse reflectance spectroscopy. J Geophys Res 114:B12101. https://doi. org/10.1029/2009JB006604
Heslop D (2009) On the statistical analysis of the rock magnetic S-ratio. Geophys J Int 178:159-161

Heslop D (2015) Numerical strategies for magnetic mineral unmixing. Earth Sci Rev 150:256-284

Heslop D, Dekkers MJ, Kruiver PP, van Oorschot IHM (2002) Analysis of isothermal remanent magnetization acquisition curves using the expectationmaximization algorithm. Geophys J Int 148:58-64

Hounslow MW, Maher BA (1999) Source of the climate signal recorded by magnetic susceptibility variations in Indian Ocean deep-sea sediments. J Geophys Res 104:5047-5061

Hu P, Zhang S, Wang H, Pan D, Tian J, Tang Z, Volinsky AA (2011) Heat treatment effects on $\mathrm{Fe}_{3} \mathrm{O}_{4}$ nanoparticles structure and magnetic properties prepared by carbothermal reaction. J Alloys Compd 509:2316-2319

Hu PX, Liu QS, Torrent J, Barrón V, Jin CS (2013) Characterizing and quantifying iron oxides in Chinese loess/paleosols: implications for pedogenesis. Earth Planet Sci Lett 369-370:271-283

Hu PX, Jiang ZX, Liu QS, Heslop D, Roberts AP, Torrent J, Barrón V (2016) Estimating the concentration of aluminum-substituted hematite and goethite using diffuse reflectance spectrometry and rock magnetism: feasibility and limitations. J Geophys Res 121:4180-4194

Hunt CP, Singer MJ, Kletetschka G, TenPas J, Verosub KL (1995) Effect of citrate-bicarbonate-dithionite treatment on fine-grained magnetite and maghemite. Earth Planet Sci Lett 130:87-94

Islam MS, Kusumoto Y, Abdulla-Al-Mamun M (2012) Novel rose-type magnetic $\left(\mathrm{Fe}_{3} \mathrm{O}_{4}, \mathrm{Y}-\mathrm{Fe}_{2} \mathrm{O}_{3}\right.$ and $\left.\mathrm{a}-\mathrm{Fe}_{2} \mathrm{O}_{3}\right)$ nanoplates synthesized by simple hydrothermal decomposition. Mater Lett 66:165-167

Jiang ZX, Liu QS, Barrón V, Torrent J, Yu YJ (2012) Magnetic discrimination between Al-substituted hematites synthesized by hydrothermal and thermal dehydration methods and its geological significance. J Geophys Res 117:B02102. https://doi.org/10.1029/2011JB008605

Jiang ZX, Liu QS, Dekkers MJ, Colombo C, Yu YJ, Barrón V, Torrent J (2014) Ferro and antiferromagnetism of ultrafine-grained hematite. Geochem Geophys Geosyst 15:2699-2712

Jiang ZX, Liu QS, Roberts AP, Barrón V, Torrent J, Zhang Q (2018) A new model for transformation of ferrihydrite to hematite in soils and sediments. Geology 46:987-990

King JW, Channell JET (1991) Sedimentary magnetism, environmental magnetism, and magnetostratigraphy. US Natl Rep Int Union Geod Geophys 1987-1990 Rev Geophys 29:358-370

Kodama KP, Dekkers MJ (2004) Magnetic anisotropy as an aid to identifying CRM and DRM in red sedimentary rocks. Stud Geophys Geod 48:747-766

Kruiver PP, Passier HF (2001) Coercivity analysis of magnetic phases in sapropel $\mathrm{S} 1$ related to variations in redox conditions, including an investigation of the S ratio. Geochem Geophys Geosyst. https://doi.org/10.1029/2001g c000181

Kruiver PP, Dekkers MJ, Heslop D (2001) Quantification of magnetic coercivity components by the analysis of acquisition curves of isothermal remanent magnetization. Earth Planet Sci Lett 189:269-276

Lagroix F, Guyodo Y (2017) A new tool for separating the magnetic mineralogy of complex mineral assemblages from low temperature magnetic behaviour. Front Earth Sci 5:61. https://doi.org/10.3389/feart.2017.00061

Langmuir D (1971) Particle size effect on the reaction goethite $=$ hematite + water. Am J Sci 271:147-156

Larrasoaña JC, Roberts AP, Rohling EJ, Winklhofer M, Wehausen R (2003) Three million years of monsoon variability over the northern Sahara. Clim Dyn 21:689-698

Liu QS, Banerjee SK, Jackson MJ, Zhu RX, Pan YX (2002) A new method in mineral magnetism for the separation of weak antiferromagnetic signal from a strong ferrimagnetic background. Geophys Res Lett 29:1565. https ://doi.org/10.1029/2002GL014699

Liu QS, Roberts AP, Torrent J, Horng CS, Larrasoaña JC (2007) What do the HIRM and S-ratio really measure in environmental magnetism? Geochem Geophys Geosyst 8:Q09011. https://doi.org/10.1029/2007GC001717

Lowrie W (1990) Identification of ferromagnetic minerals in a rock by coercivity and unblocking temperature properties. Geophys Res Lett 17:159-162

Lyons R, Oldfield F, Williams E (2010) Mineral magnetic properties of surface soils and sands across four North African transects and links to climatic gradients. Geochem Geophys Geosyst 11:Q08023. https://doi. org/10.1029/2010GC003183

Maher BA (1986) Characterisation of soils by mineral magnetic measurements. Phys Earth Planet Inter 42:76-92 
Maher BA, Alekseev A, Alekseeva T (2003) Magnetic mineralogy of soils across the Russian Steppe: climatic dependence of pedogenic magnetite formation. Palaeogeogr Palaeoclimatol Palaeoecol 201:321-341

Maher BA, Karloukovski WV, Mutch TJ (2004) High-field remanence properties of synthetic and natural submicrometre haematites and goethites: significance for environmental contexts. Earth Planet Sci Lett 226:491-505

Mehra OP, Jackson ML (1960) Iron oxide removal from soils and clays by dithionite-citrate system buffered with sodium bicarbonate. Clays Clay Miner 7:317-327

Memon M, Memon KS, Akhtar MS, Stüben D (2009) Characterization and quantification of iron oxides occurring in low concentration in soils. Commun Soil Sci Plant Anal 40:162-178

Oldfield F, Chiverrell RC, Lyons R, Williams E, Shen Z, Bristow C, Bloemendal J, Torrent J, Boyle JF (2014) Discriminating dusts and dust sources using magnetic properties and hematite: goethite ratios of surface materials and dust from North Africa, the Atlantic and Barbados. Aeolian Res 13:91-104

Özdemir Ö, Dunlop DJ (2014) Hysteresis and coercivity in hematite. J Geophys Res 119:2582-2594

Quinton EE, Dahms DE, Geiss CE (2011) Magnetic analyses of soils from the Wind River Range, Wyoming, constrain rates and pathways of magnetic enhancement for soils from semiarid climates. Geochem Geophys Geosyst 12:Q07Z30. https://doi.org/10.1029/2011gc003728

Reynolds RL, Cattle SR, Moskowitz BM, Goldstein HL, Yauk K, Flagg CB, Berquó TS, Kokaly RF, Morman S, Breit GN (2014) Iron oxide minerals in dust of the Red Dawn event in eastern Australia, September 2009. Aeolian Res 15:1-13

Roberts AP, Florindo F, Chang L, Heslop D, Jovane L, Larrasoaña JC (2013) Magnetic properties of pelagic marine carbonates. Earth Sci Rev 127:111-139

Robertson DJ, France DE (1994) Discrimination of remanence-carrying minerals in mixtures, using isothermal remanent magnetisation acquisition curves. Phys Earth Planet Inter 82:223-234

Robinson SG (1986) The late Pleistocene palaeoclimatic record of North Atlantic deep-sea sediments revealed by mineral-magnetic measurements. Phys Earth Planet Inter 42:22-47

Rochette P, Mathé PE, Esteban L, Rakoto H, Bouchez JL, Liu QS, Torrent J (2005) Non-saturation of the defect moment of goethite and fine-grained hematite up to 57 Teslas. Geophys Res Lett 32:L22309. https://doi. org/10.1029/2005GL024196

Rosenbaum JG, Reynolds RL, Adam DP, Drexler J, Sarna-Wojcicki AM, Whitney GC (1996) Record of middle Pleistocene climate change from Buck Lake, Cascade Range, southern Oregon-evidence from sediment magnetism, trace-element geochemistry and pollen. Geol Soc Am Bull 108:1328-1341

Scheinost AC, Chavernas A, Barrón V, Torrent J (1998) Use and limitations of second-derivative diffuse reflectance spectroscopy in the visible to nearinfrared range to identify and quantify Fe oxide minerals in soils. Clays Clay Miner 46:528-536
Schulze DG (1981) Identification of soil iron oxide minerals by differential X-ray diffraction. Soil Sci Soc Am J 45:437-440

Schwertmann U (1985) The effect of pedogenic environments on iron oxide minerals. Adv Soil Sci 1:171-200

Schwertmann U (1991) Solubility and dissolution of iron oxides. Plant Soil 130:1-25

Shi MN, Wu HC, Zhang SH, Li HY, Yang TS, Liu W, Liu H (2014) Weekly cycle of magnetic characteristics of the daily $\mathrm{PM}_{2.5}$ and $\mathrm{PM}_{2.5-10}$ in Beijing, China. Atmos Environ 98:357-367

Stober JC, Thompson R (1979) An investigation into the source of magnetic minerals in some Finnish lake sediments. Earth Planet Sci Lett 45:464-474

Stoner JS, Channell JET, Hillaire-Marcel C (1996) The magnetic signature of rapidly deposited detrital layers from the deep Labrador Sea: relationships to North Atlantic Heinrich Layers. Paleoceanography 11:309-325

Thompson R (1986) Modelling magnetization data using SIMPLEX. Phys Earth Planet Inter 42:113-127

Thompson R, Oldfield F (1986) Environmental magnetism. Allen and Unwin, London, p 227

Torrent J, Barrón V (2002) Diffuse reflectance spectroscopy of iron oxides. In: Hubbard AT (ed) Encyclopedia of Surface and Colloid Science. Marcel Dekker, New York, pp 1438-1446

Torrent J, Schwertmann U, Schulze DG (1980) Iron oxide mineralogy of some soils of two river terrace sequences in Spain. Geoderma 23:191-208

Torrent J, Liu QS, Bloemendal J, Barrón V (2007) Magnetic enhancement and iron oxides in the upper Luochuan loess-paleosol sequence, Chinese Loess Plateau. Soil Sci Soc Am J 71:1570-1578

van Oorschot IHM, Dekkers MJ (1999) Dissolution behavior of fine-grained magnetite and maghemite in the citrate-bicarbonate-dithionite extraction method. Earth Planet Sci Lett 167:283-295

van Oorschot IHM, Grygar T, Dekkers MJ (2001) Detection of low concentrations of fine-grained iron oxides by voltammetry of microparticles. Earth Planet Sci Lett 193:631-642

van Velzen AJ, Zijderveld JDA (1995) Effects of weathering on single-domain magnetite in Early Pliocene marine marls. Geophys J Int 121:267-278

Vandenberghe RE, Barerro CA, da Costa GM, Van San E, De Grave E (2000) Mössbauer characterization of iron oxides and (oxy)hydroxides: the present state of the art. Hyperfine Interact 126:247-259

Verosub KL, Fine P, Singer MJ, TenPas J (1993) Pedogenesis and paleoclimate: interpretation of the magnetic susceptibility record in Chinese loess/ paleosol sequences. Geology 21:1011-1014

Yamazaki T, loka N (1997) Environmental rock-magnetism of pelagic clay: implications for Asian eolian input to the North Pacific since the Pliocene. Paleoceanography 12:111-124

\section{Publisher's Note}

Springer Nature remains neutral with regard to jurisdictional claims in published maps and institutional affiliations.

\section{Submit your manuscript to a SpringerOpen ${ }^{\odot}$ journal and benefit from:}

- Convenient online submission

- Rigorous peer review

- Open access: articles freely available online

- High visibility within the field

Retaining the copyright to your article

Submit your next manuscript at springeropen.com 